\section{Autotransplantation of a Mandibular Third Molar: A Case Report with 5 Years of Follow-up}

Mauro Henrique Chagas e Silva, Mariane Floriano Lopes Santos Lacerda, Maria das Graças Afonso Miranda Chaves, Celso Neiva Campos
Department of Clinical Dentistry, Federal University of Juiz de Fora, Juiz de Fora, MG, Brazil

Correspondence: Dr. Celso Neiva Campos, Rua Lindalva de Paula Ribeiro, 240, Bosque Imperial, 36036-466 Juiz de Fora, MG, Brasil. Tel: +55-32-3215-3434. e-mail: cncampos@terra.com.br
This paper describes the autologous transplantation of a mandibular right third molar to replace the residual roots of the second molar in the same quadrant, preserving function and aesthetics. A 5-year clinical and radiographic follow-up was undertaken. After transplantation, the donor tooth received endodontic treatment and placement of calcium hydroxide, which was periodically replaced every 3 months until the filling of the root canals, totalizing a period of 1-year, when apical closure was confirmed. The tooth was in perfect functional and aesthetic conditions 5 years after beginning of treatment. Autotransplantation is a feasible option for replacing missing teeth when a donor tooth is available. The autotransplantation of a right mandibular third molar with compromised function and aesthetics to replace the residual roots resulting from coronal destruction due to extensive carious lesion of the second molar in the same quadrant was a viable treatment alternative.
Key Words: autotransplantation, calcium hydroxide, dental caries, Endodontics, root canal treatment.

\section{Introduction}

One of the goals of dentistry is the replacement of missing teeth to restore masticatory function and aesthetics. Conventionally, missing teeth have been replaced with removable prostheses, which often cause discomfort to the patient, or fixed prostheses, which involve the preparation of one or more healthy teeth.

In 1953, Fong reported the successful autotransplantation of third molars and was followed by other authors who validated the procedure (1-6). At present, due to advances in osseointegrated implants, autologous tooth transplantation or autotransplantation is rarely indicated. However, the placement of osseointegrated implants is contraindicated in growing patients, making autotransplantation a viable alternative for young patients (7).

Although autotransplantation is a rehabilitation method that achieves high success rates, there is a gap in the discussion of this treatment in the curricula of dental schools, and in oral and maxillofacial surgery textbooks (8).

The purpose of this paper is to describe the autologous transplantation of a right mandibular third molar to replace the residual roots of the second molar in the same quadrant, preserving function and aesthetics.

\section{Case Report}

A 19-year-old Caucasian female patient sought treatment for residual roots of the right mandibular second molar and a partially erupted third molar in the same quadrant (Fig. 1A). The decision was to extract the residual roots and impacted tooth. Implant placement and other details about the treatment were explained to the patient, but she did not want to have an implant in the near future. Thus, autologous tooth transplantation was suggested to prevent bone resorption at the site of the mandibular second molar.

The procedure was performed in one stage. The third molar was extracted and placed back into the extraction socket until the residual roots of the second molar were removed and the recipient site was prepared with \#4 surgical carbide round bur in a low-speed handpiece under sterile saline irrigation. The donor tooth was then placed into the recipient socket and its fitting was evaluated. Stabilization was achieved using a $0.8 \mathrm{~mm}$ stainless steel wire and 3-0 nylon sutures. The enamel on the buccal surfaces of the autotransplanted third molar and adjacent tooth (right mandibular first molar) was etched with 37\% phosphoric acid for $30 \mathrm{~s}$. Adhesive was then applied to the enamel and the stainless steel wire was fixed on the etched enamel with light-cured composite resin. Since only one tooth was used for stabilization, the temporary fixation had semi-rigid characteristics and the autotransplanted tooth remained splinted for 2 weeks (Fig. 1B,C).

For the post-surgical period, the patient was prescribed with an antibiotic (Amoxicillin $500 \mathrm{mg}$ every $8 \mathrm{~h}$ for 7 days after the procedure), an analgesic (Paracetamol 750 mg every $6 \mathrm{~h}$ for 3 days), liquid and pasty diet for 1 week and mouthrinses with a $0.12 \%$ chlorhexidine solution for the same period.

Pulp extirpation, cleaning and shaping of the root canals were performed 7 days after the surgical procedure. All 
endodontic procedures were carried out under rubber dam isolation following a strict aseptic technique. Stainless steel K-files (Maillefer Instruments, Ballaigues, Switzerland) were used for instrumentation. The root canals were prepared to a size $80 \mathrm{~K}$-file, and then were enlarged from the middle third to the cervical portion using \# 1 to \# 4 Gates-Glidden drills (Maillefer Instruments). The canals were irrigated with $5.25 \%$ sodium hypochlorite. Regenerative endodontic therapy was not indicated and the canals were filled with analytical reagent calcium hydroxide paste (CalenPMCC; SS White, Rio de Janeiro, RJ, Brazil) as intracanal medicament. Special care was taken to ensure that the
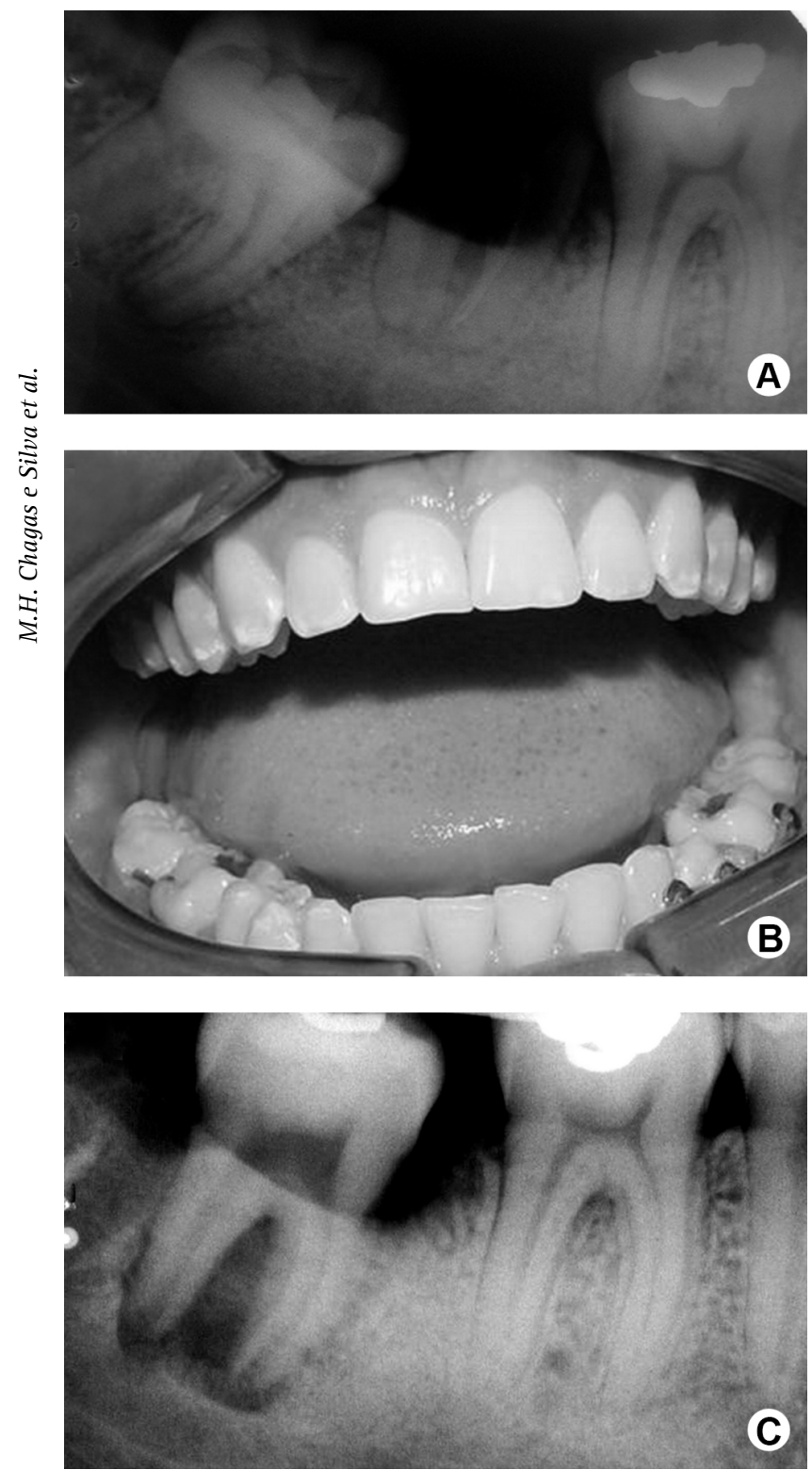

Figure 1. A: Periapical radiograph before surgery. B: Stabilization of the autotransplanted tooth with stainless-steel wire and light-cured composite resin. C: Periapical radiograph showing the autotransplanted tooth in the recipient socket and splinted to the adjacent tooth for stabilization. canals were completely filled with calcium hydroxide paste. As the canals were not completely filled in the first attempt (Fig. 2A), the procedure was repeated (Fig. 2B).

The patient returned every 3 months during 12 months to assess pain, root resorption, mobility of the autotransplanted tooth, periodontal pocket and bone remodeling, to replace the calcium hydroxide with fresh material, and for periapical radiographs (Fig. 3A-C). One year after start of the treatment, apical closure was confirmed (Fig. 3C), the canals were filled with gutta-percha and endodontic sealer (Endofill; Dentsply Ind. e Com. Ltda., Petrópolis, RJ, Brazil) using the vertical condensation technique, and the endodontic treatment was completed (Fig. 3D). The access cavity was restored with light-cured composite resin (Fig. 4A-C).

Clinical and radiographic follow-ups were conducted 16 , 25 and 60 months after autotransplantation and showed that the treatment was successful (Fig. 5A-C).

The institutional Research Ethics Committee approved the study protocol and the study conforms to the provisions of the World Medical Association Declaration of Helsinki (June 1964) and subsequent amendments. The patient signed an informed consent for the procedures and for use of clinical data for scientific purposes and publication. Patient anonymity was assured.
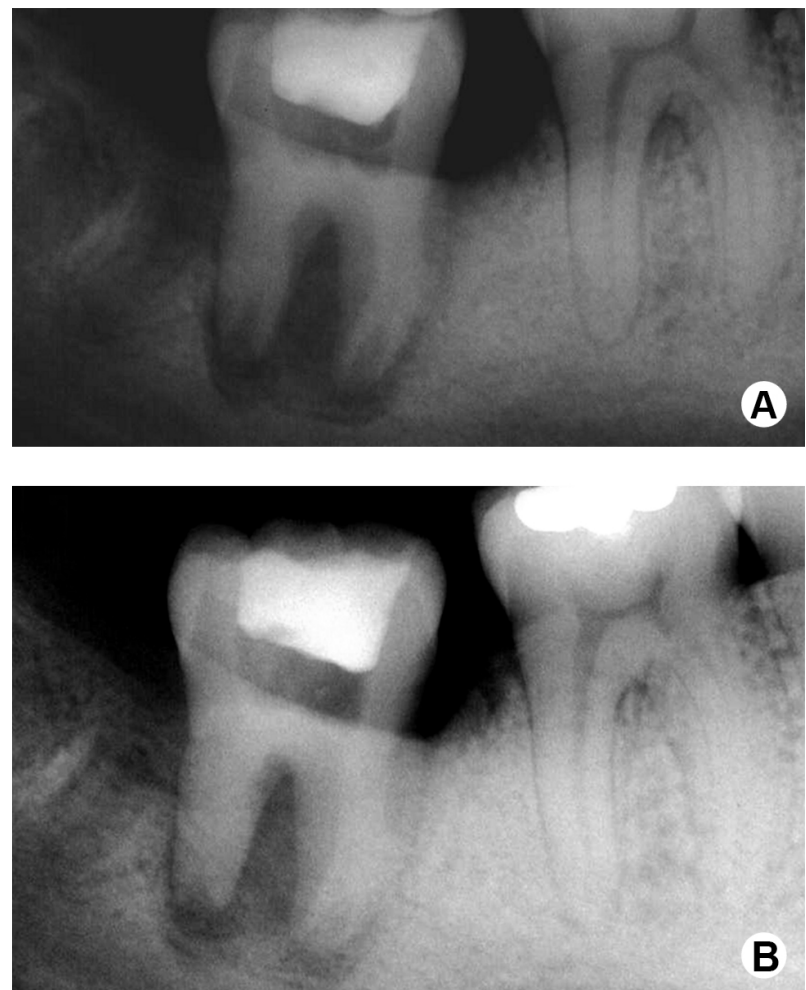

Figure 2. A: Root canals not properly filled with calcium hydroxide paste. B: Autotransplanted tooth after a second application of calcium hydroxide as intracanal dressing. 


\section{Discussion}

Dental rehabilitation after the loss of one or more teeth may be achieved with several techniques, including removable or fixed prostheses, osseointegrated implants, or autotransplantation. The first studies reporting on successful transplants of autologous teeth were published in the 1950s (6).

Autotransplantation is defined as the transplantation of teeth from one site to another in the same individual into extraction sites or surgically prepared sockets (10). The advantages of autotransplantation include the possibility of maintaining the viability of the periodontal ligament, orthodontic movement and proprioception, and preservation of the alveolar bone and gingival graft with a natural contour. Moreover, autotransplantation can be performed in growing patients. The cost of autotransplantation is low compared to that of osseointegrated implants because the procedure is performed in one stage and no prosthesis is required (8).

In the reported case, despite the patient's adult age and suitability for placement of an osseointegrated implant, the autotransplantation was chosen because it involved a single surgical phase, the donor tooth was in good conditions and the whole procedure had a low cost.

However, autotransplantation has some disadvantages, including the fact that it is technically demanding because surgical trauma can cause irreversible damage to the periodontal ligament, a donor tooth compatible with the recipient socket must be available, the longterm success rates of autotransplantation may not equal those of osseointegrated implants, endodontic therapy is required in cases of donor teeth with fully developed roots, and complications such as ankylosis, inflammatory root resorption and dental caries may occur (9).

A set of criteria for evaluating the success or failure of autotransplantation needs to be established. A key factor for the success of the procedure is to maintain the viability of periodontal ligament cells of the transplanted tooth. Because periodontal ligament cells are very sensitive to osmotic changes, their viability may be reduced if extraoral dry time is long (2). It is believed that the preservation of the epithelial cell rests of Malassez prevents root resorption and maintains the periodontal ligament space, thereby preventing ankylosis (11). Other factors, such as patient age $<20$ years, donor tooth with immature roots, minimally traumatic surgical procedures and surgeon's
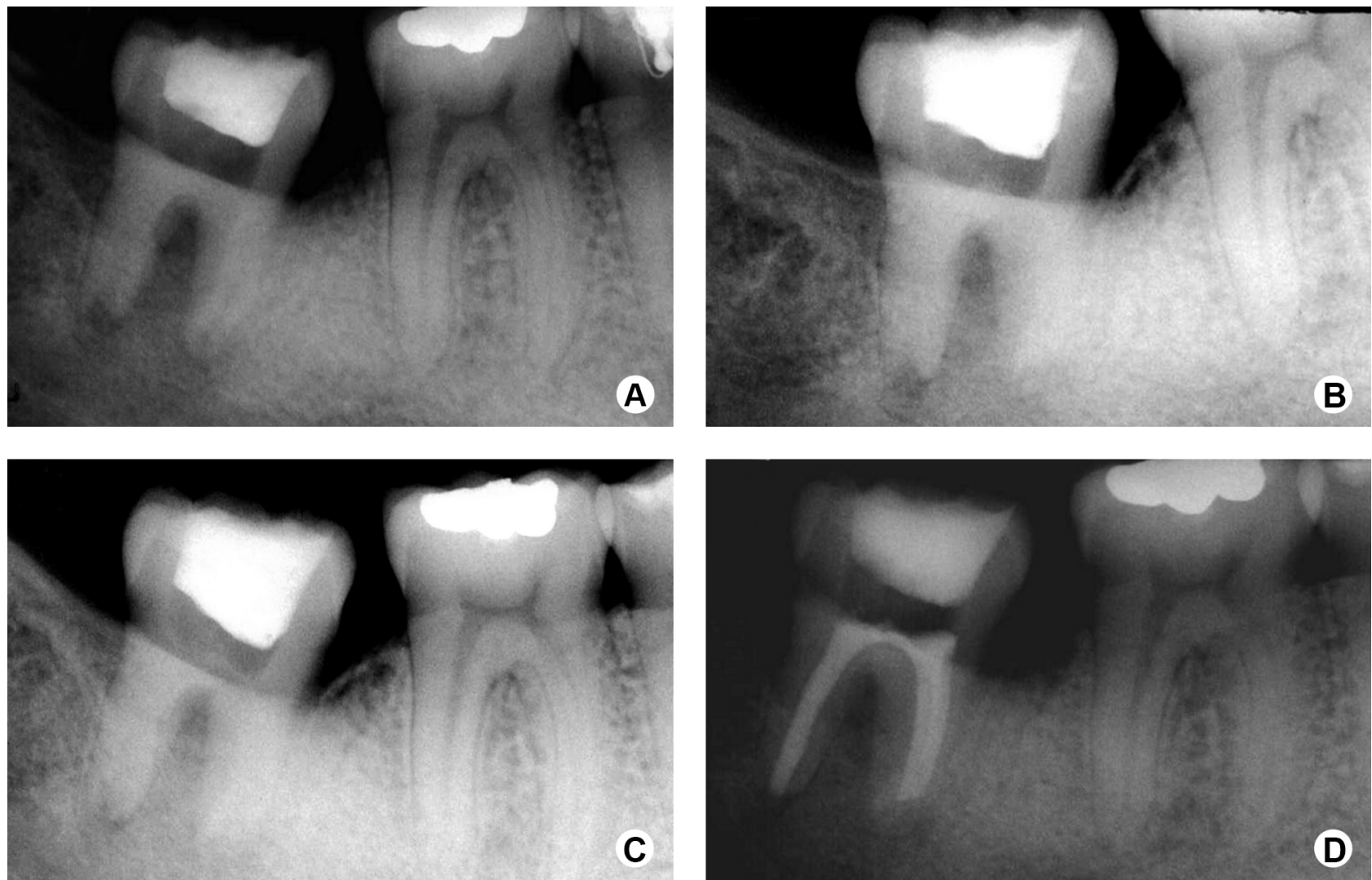

Figure 3. Radiographs taken after the calcium hydroxide was replaced with fresh material. A, B and C: 3, 6 and 9 months after autotransplantation, respectively. The presence of new bone formation can be noticed in all images. D: Autotransplanted tooth after completion of endodontic treatment 12 months after surgery. 
experience are associated with a good prognosis $(1,12)$. The success of the procedure also depends on adequate bony support at the recipient site and absence of acute or chronic inflammation (13). In this case the patient was 19 years old, had adequate bone support at the donor site, the
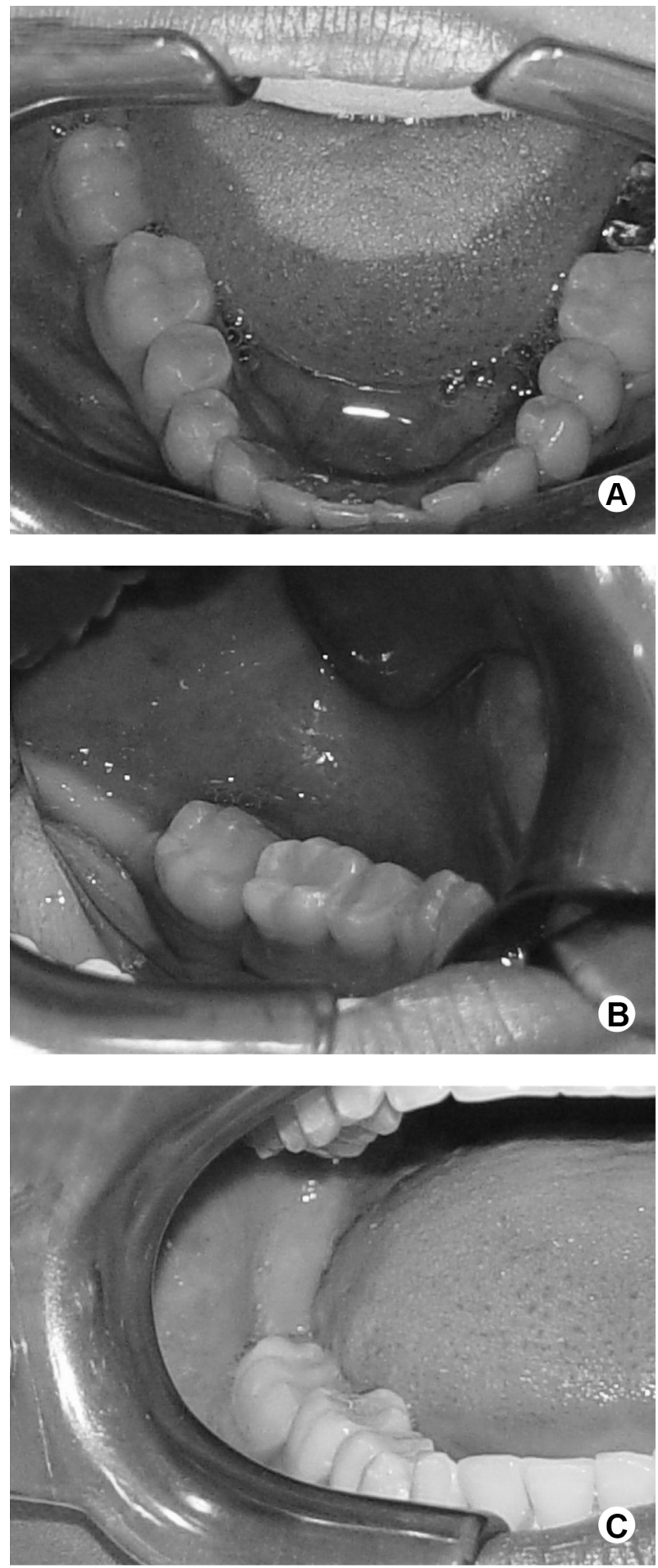

Figure 4. Occlusal view (A), lingual view (B) and buccal view (C) of the autotransplanted tooth, showing a perfect gingival contour 12 months after surgery. The tooth was restored with light-cured composite resin. development of the donor tooth was not completed and the surgical procedure was minimally traumatic, creating favorable conditions for the procedure.

On the other hand, unsuccessful autotransplantation is usually associated with inadequate surgical technique (trauma), donor tooth with contaminated root cementum, periodontal pocket depth $\geq 4 \mathrm{~mm}$, and patients aged $\geq 40$ years (5). In a retrospective study on the survival of autologous tooth transplants, Yoshino et al. (6) reported that the main reasons for autotransplantation failure were periodontal attachment loss (54.9\%), root resorption
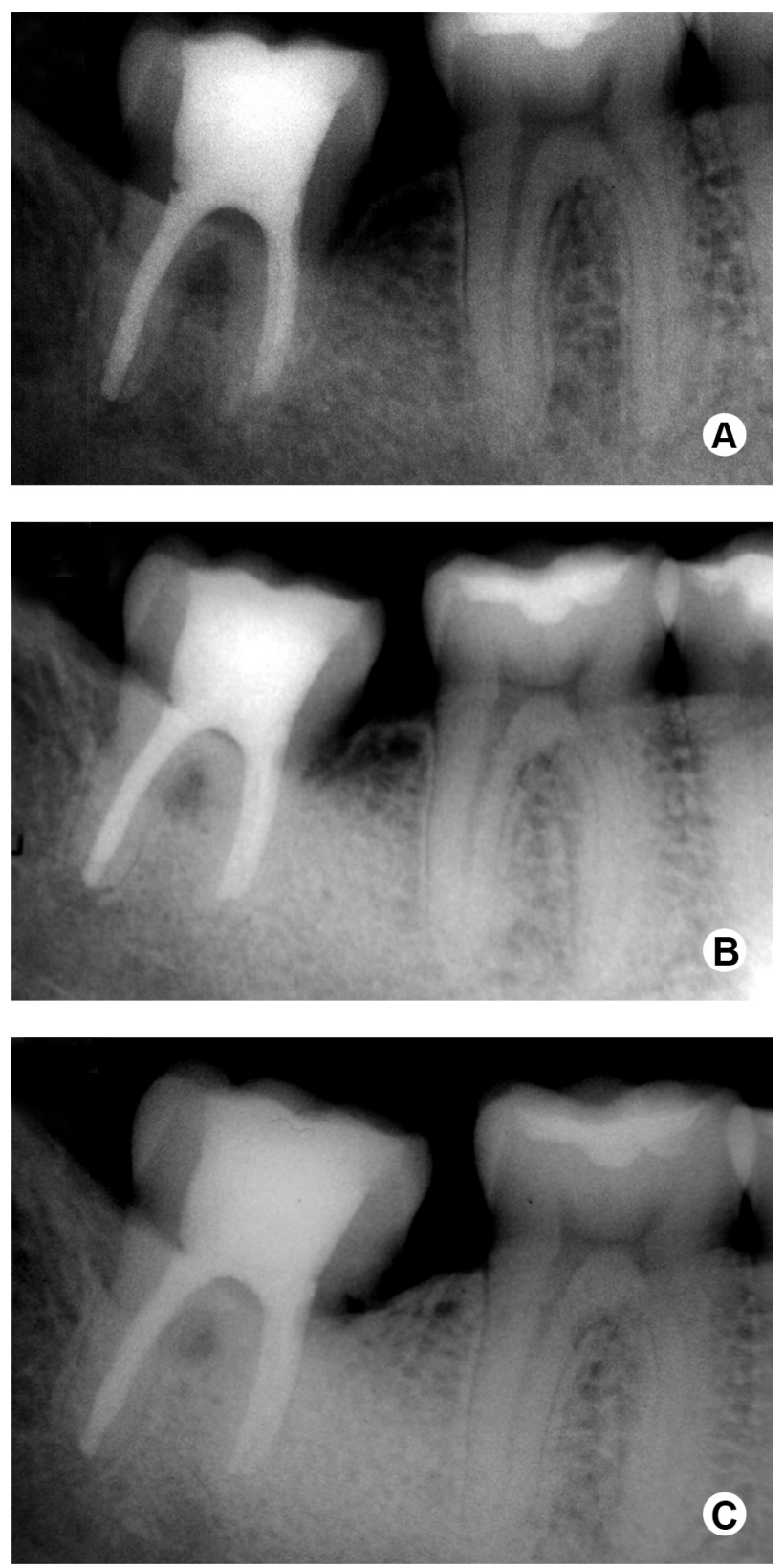

Figure 5. Radiographs of the autotransplanted tooth 16 months (A), 25 months (B) and 60 months (C) after endodontic treatment, showing possible signs of inflammatory cervical resorption mesial side and root ankylosis on the mesial roots. 
$(26.5 \%)$, dental caries $(4.0 \%)$, root fracture $(2.9 \%)$ and other causes $(11.8 \%)$.

In the present case, there were no possible signs of inflammatory cervical external resorption and ankylosis at 60 months follow-up (Fig. 5B,C), which can extend the treatment time and lead to more severe complications, including loss of the transplanted tooth. However, the clinical examination showed no periodontal pocket, no mobility and the percussive clinical test did not produce the characteristic metallic sound.

There is a consensus amongst authors that wellperformed surgical procedures are essential to ensure minimal trauma to the root surface $(1,3,4,6,13,14)$. The findings of a clinical-radiographic study with 25 autotransplanted third molars suggested the use of burs under irrigation with normal saline in the preparation of the donor site (3). The donor tooth is then extracted and placed into the recipient socket for fit assessment. If further adjustment of the recipient socket is necessary, the donor tooth should be placed back into the extraction socket or kept in saline. In the reported case as well as in the case reported by Teixeira et al. (9), the donor site was prepared with round burs in low-speed surgical handpieces under sterile saline irrigation and the donor tooth was maintained in its own socket until the preparation and adjustment of the donor site after extraction. In a recent study, piezosurgery with specific device tip vibration frequencies was used in the autotransplantation of unerupted third molars to facilitate the removal of the donor teeth from the bone with little injury to periodontal fibers or bud follicles and reduce the occurrence of ankylosis or root resorption of the transplanted teeth (15).

Long-term rigid splinting of transplanted teeth may negatively affect the healing process. On the other hand, the use of a non-rigid splint for 7 to 10 days may stimulate periodontal ligament and alveolar bone regeneration (2). In this case, a non-rigid splint was maintained for 2 weeks.

Autotransplantation of teeth with immature roots is associated with increased success rates, possible pulp revascularization, maintenance of soft- and hard-tissue health and eruptive potential, and enhancement of alveolar bone. In contrast, it is expected that for teeth with mature roots, the rupture of the neurovascular bundle during tooth extraction will exclude the possibility of revascularization, resulting in pulp necrosis. In this situation, endodontic therapy should be performed within 15 days after transplantation. Andreasen et al. (16) reported that in replantation of 400 avulsed teeth for pulp healing there were 110 teeth with immature apices and among them 94 teeth with chances for pulp revascularization. Revascularization occurred only in 32 teeth (34\%). A multivariate analysis revealed that pulp revascularization was more frequent in teeth with shorter distances from the apical foramen to the pulp horns. In the reported case the donor tooth had nearly fully formed roots, more than $2 / 3$ of the root development with sufficient length for a good insertion of bone and periodontal ligament, hence the choice for the apical closure with a calcium hydroxide dressing, avoiding the revascularization procedure.

The use of calcium hydroxide as an intracanal dressing is required as part of the endodontic treatment because the high $\mathrm{pH}$ and antimicrobial properties of this compound may contribute to the prevention of root resorption and stimulation of the healing process $(9,10,13,17)$. In this case, a calcium hydroxide dressing was used in addition to the already described properties to stimulate the process of apical closure. The depositions of mineral tissue and the conformation of the apical region shown by radiographic examination at 12 months suggest that the closure occurs (Fig. 3C).

Kvint et al. (1) performed autotransplantation in 215 patients with a mean follow-up of 4.8 years and reported an overall success rate of $81 \%$ and a $100 \%$ success rate of premolars autotransplanted to the maxillary incisor region. Similar findings were reported by Bae et al. (2), who obtained an $84 \%$ autotransplantation success rate in a case series. Yoshino et al. (6), in a retrospective study of 614 autotransplanted teeth reported that the cumulative success rate of transplanted teeth with mature roots was $90.1 \%$ at 5 years, $70.5 \%$ at 10 years, and $55.6 \%$ at 15 years. The authors also reported that the success rate was $90.2 \%$ at 10 years for Branemark implants, and $89.1 \%$ at 10 years for fixed partial dentures. These studies suggest that autotransplantation is a viable treatment option with good results for the replacement of missing teeth. This rehabilitation technique may play an important role in situations where patients have limited financial resources, in public health services, and for restoration of function and aesthetics in growing patients.

The high cost of osseointegrated implants and preparation of healthy teeth to provide support for fixed partial dentures are factors that may discourage the patient to replace a missing tooth, causing aesthetic and masticatory problems.

Autotransplantation is a relatively simple, low-cost treatment option for missing teeth with good success rates (18). In the present case, the technique was effective in restoring function and aesthetics.

\section{Resumo}

0 objetivo deste trabalho foi descrever o transplante autógeno de um terceiro molar inferior direito para substituir as raizes residuais do segundo molar no mesmo quadrante, preservando a função e a estética. Foi realizado acompanhamento clínico e radiográfico por 5 anos. Após o transplante, o dente doador recebeu tratamento endodôntico e 
colocação de hidróxido de cálcio, o qual foi substituído periodicamente a cada 3 meses, até a obturação dos canais radiculares, totalizando periodo de 1 ano quando então, o fechamento apical foi confirmado. 0 dente encontra-se em perfeitas condições funcionais e estéticas após 5 anos do início do tratamento. 0 autotransplante é uma opção viável para a substituição de dentes perdidos quando um dente doador está disponivel. 0 autotransplante de um terceiro molar inferior direito com comprometimento estético e funcional afim de substituir raizes residuais (resultado de um processo cariogênio extenso) de um segundo molar do mesmo quadrante foi um tratamento alternativo viável.

\section{References}

1. Kvint $S$, Lindsten $R$, Magnusson $A$, Nilsson $P$, Bjerklin $K$. Autotransplantation of teeth in 215 patients. A follow-up study. Angle Orthod 2010; 80:446-451.

2. Bae JH, Choi YH, Cho BH, Kim YK, Kim SG. Autotransplantation of teeth with complete root formation: a case series. J Endod 2010;36:14221426.

3. Akiyama $\mathrm{Y}$, Fukuda $\mathrm{H}$, Hashimoto $\mathrm{K}$. A clinical and radiographic study of 25 autotransplanted third molars. J Oral Rehabil 1998;25:640-644.

4. Yan $\mathrm{Q}$, Li B, Long X. Immediate autotransplantation of mandibular third molar in China. Oral Surg Oral Med Oral Pathol Oral Radiol Endod 2010;110:436-440.

5. Sugai T, Yoshizawa M, Kobayashi T, Ono K, Takagi R, Kitamura N, et al.. Clinical study on prognostic factors for autotransplantation of teeth with complete root formation. Int J Oral Maxillofac Surg 2010;39:11931203.

6. Yoshino K, Kariya N, Namura D, Noji I, Mitsuhashi K, Kimura H, et al.. A retrospective survey of autotransplantation of teeth in dental clinics. J Oral Rehabil 2012;39:37-43.

7. Thomas S, Turner SR, Sandy JR. Autotransplantation of teeth: is there a role? Br J Orthod 1998;25:275-282.

8. Baviz JB. Autotransplantation of teeth: a procedure that gets no respect. Oral Surg Oral Med Oral Pathol Oral Radiol Endod 2010;110:441.

9. Teixeira CS, Pasternak Jr. B, Vansan LP, Sousa-Neto MD. Autogenous transplantation of teeth with complete root formation: two case reports. Int Endod J 2006;39:977-985.

10. Tsurumachi T, Kuno T. Autotransplantation of a maxillary first premolar to replace an ankylosed maxillary incisor: 7-year follow-up. Int Endod J 2011;44:863-875.

11. Struys T, Schuermans J, Corpas L, Politis C, Vrielinck L, Schepers S, et al.. Proliferation of epithelial rests of Malassez following autotransplantation of third molars: a case report. J Med Case Rep 2010;4:328.

12. Tirali R, Sar C, Ates U, Kizilkaya M, Cehreli B. Autotransplantation of a supernumerary tooth to replace a misaligned incisor with abnormal dimensions and morphology: 2- year follow-up. Case Rep Dent 2013; 2013:1-5.

13. Heer J. Calcium hydroxide therapy and bony regeneration following autogenous tooth transplantation: case report and three year follow up. Br Dent J 2007;203:403-405.

14. Smith JJ, Wayman BE. Successful autotransplantation. J Endod 1987;13:77-80.

15. Koszowski R, Morawiec T, Bubilek-Bogacz A. Use of the piezosurgery technique for cutting bones in the autotransplantation of unerupted third molars. Int J Periodontics Restorative Dent 2013;33:477-481.

16. Andreasen JO, Borum MK, Jacobsen HL, Andreasen FM. Replantation of 400 avulsed permanent incisors. 2. Factors related to pulpal healing. Endod Dent Traumatol 1995;11:59-68.

17. Singh $R$, Khatter $R, B a l ~ R, B a l ~ C$. Intracanal medications versus placebo in reducing postoperative endodontic pain - a double- blind randomized clinical trial. Braz Dent J 2013;24:25-29.

18. Kang J, Chang H, Hwang Y, Hwang I, Oh W, Lee B. Autogenous tooth transplantation for replacing a lost tooth: case reports. Restor Dent Endod 2013; 38:48-51. 